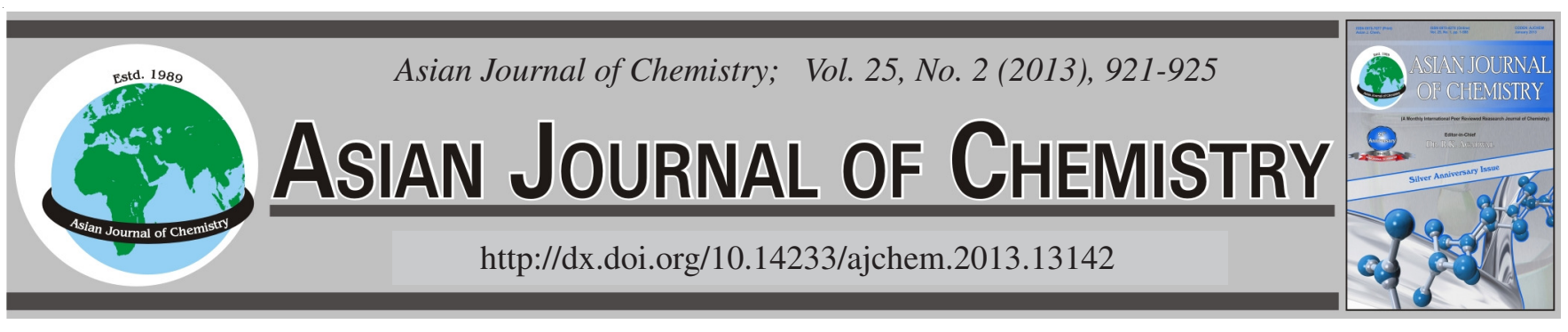

\title{
Oxidation of Some $\alpha$-Hydroxy Acids by Pyridinium Fluorochromate in Aqueous Acetic Acid Media-A Kinetic and Mechanistic Study
}

\section{S. ZAheer Ahmed ${ }^{1}$, S. Syed Shafi ${ }^{2, *}$ and S. Sheik MAnSOOR ${ }^{3}$}

${ }^{1}$ Department of Chemistry, Islamiah College, Vaniyambadi-635 752, India

${ }^{2}$ Department of Chemistry, Thiruvalluvar University, Serkadu, Vellore-632106, India

${ }^{3}$ Department of Chemistry, C. Abdul Hakeem College, Melvisharam-632 509, India

*Corresponding author: E-mail: suban_shafi@yahoo.com

\section{INTRODUCTION}

Chromium(VI) reagents are widely used in organic chemistry for oxidation of primary and secondary alcohols to carbonyl compounds. A variety of compounds containing chromium(VI) have proved to be versatile reagents capable of oxidizing almost every oxidiazable functional group ${ }^{1}$. A number of new chromium(VI) containing compounds, with heterocyclic bases, like pyridinium chlorochromate ${ }^{2}$, pyridinium bromochromate ${ }^{3}$, quinoliium chlorochromate ${ }^{4}$, benzimidazolium fluorochromate ${ }^{5}$, quinolinium bromochromate $^{6}$, imidazolium fluorochromate ${ }^{7}$, pyridinium fluorochromate $(\mathrm{PFC})^{8}$, tributylammonium chlorochromate (TriBACC) ${ }^{9}$, tripropylammonium fluorochromate (TriPAFC) ${ }^{10}$, benzyltrimethyl ammonium fluorochromate (BTMAFC) ${ }^{11}$ and imidazoliun dichromate ${ }^{12}$ have been developed to improve the selectivity of oxidation of organic compounds. The kinetics and mechanism of oxidation of hydroxyl acids by various oxidants have been reported ${ }^{13-19}$. However, the kinetics of oxidation of hydroxyl acids by pyridinium fluorochromate, a $\mathrm{Cr}(\mathrm{VI})$ reagent has not yet been studied. This prompted us to undertake the present investigation. The present work reports the kinetics of oxidation of $\alpha$-hydroxy acids by pyridinium fluorochromate and evaluates the reaction constants.

\section{EXPERIMENTAL}

Pyridine and chromium trioxide were obtained from Fluka (Buchs, Switzerland). The hydroxy acids used were glycolic acid, lactic acid and mandelic acid. Acetic acid was purified by standard method and the fraction distilling at $118^{\circ} \mathrm{C}$ was collected.

Preparation of pyridinium fluorochromate: Pyridinium fluorochromate has been prepared from pyridine, $40 \%$ hydrofluoric acid and chromium trioxide in the molar ratio 1:1.3:1 at $0{ }^{\circ} \mathrm{C}$. Pyridinium fluorochromate is obtained as yellow orange crystals. It is non-hygroscopic, light insensitive on storage ${ }^{8}$. The purity of pyridinium fluorochromate was checked by the iodometric method.

Kinetic measurements: The pseudo-first-order conditions were attained by maintaining a large excess $(\times 15$ or more) of $\alpha$-hydroxy acids over pyridinium fluorochromate. The solvent was $50 \%$ acetic acid $+50 \%$ water $(\mathrm{v} / \mathrm{v})$, unless specified otherwise. The reactions were followed, at constant temperatures $( \pm 0.01 \mathrm{~K})$, by monitoring the decrease in $[\mathrm{PFC}]$ spectrophotometrically at $366 \mathrm{~nm}$. The pseudo-first-order rate constant. $\mathrm{k}_{\mathrm{obs}}$, was evaluated from the linear $(r=0.990$ to 0.999$)$ plots of $\log$ [PFC] against time for up to $80 \%$ reaction. The second order rate constant $\mathrm{k}_{2}$, was obtained from the relation $\mathrm{k}_{2}=\mathrm{k}_{\mathrm{obs}} /[\mathrm{HA}]$. 
Data analysis: Correlation analysis were carried out using Microcal origin (version 6) computer software. The goodness of the fit was discussed using the correlation coefficient ( $\mathrm{r}$ in the case of simple linear regression and $\mathrm{R}$ in the case of multiple linear regression) and standard deviation (SD).

\section{RESULTS AND DISCUSSION}

Product analysis: Product analysis was carried out under kinetic conditions i.e. with excess of the reductant over pyridinium fluorochromate. In a typical experiment, mandelic acid $(15.2 \mathrm{~g}, 0.1 \mathrm{~mol})$, perchloric acid $(0.1 \mathrm{~mol})$ and pyridinium fluorochromate $(0.01 \mathrm{~mol})$ were dissolved in acetic acidwater mixture $(50 \%+50 \%)$ and the solution was allows to stand in the dark for about $24 \mathrm{~h}$ to ensure completion of the reaction. The residue was treated with an excess $(200 \mathrm{~mL})$ of a saturated solution of 2,4-dinitro phenylhydrazine in $1 \mathrm{~mol}$ $\mathrm{dm}^{-3} \mathrm{HCl}$ and kept overnight in a refrigerator. The precipitated 2,4-dinitro phenyl hydrozone (DNP) was filtered off, dried and recrystallized from ethanol. The product was identical (mp and mixed $\mathrm{mp}$ ) to an authentic sample of the DNP of phenyl glyoxylic acid.

Stoichiometric studies: The stoichiometric studies for the oxidation of hydroxy acids by pyridinium fluorochromate were carried out with oxidant in excess. The solvent composition $50 \%$ acetic acid $+50 \%$ water $(\mathrm{v} / \mathrm{v})$ and $\left[\mathrm{H}^{+}\right]$were maintained as in the corresponding rate measurements. The temperature was maintained at $303 \mathrm{~K}$. The hydroxy acids and pyridinium fluorochromate were mixed in the ratio 1:4, 1:5, 1:6 and were allowed to react for $24 \mathrm{~h}$ at $303 \mathrm{~K}$. The concentration of unreacted pyridinium fluorochromate was determined. $\Delta[\mathrm{PFC}]$ was calculated. The stoichiometry was calculated from the ratio between [HA] and [PFC].

Stoichiometric analysis showed that the following overall reaction.

$$
\begin{gathered}
\mathrm{RCH}(\mathrm{OH}) \mathrm{COOH}+\mathrm{O}_{2} \mathrm{CrFO}-\mathrm{PyH}^{+}+\mathrm{H}^{+} \rightarrow \\
\mathrm{RCOCOOH}+\mathrm{H}_{2} \mathrm{O}+\mathrm{OCrFO}-\mathrm{PyH}^{+}
\end{gathered}
$$

Effect of varying pyridinium fluorochromate concentration: The concentration of pyridinium fluorochromate was varied in the range of $0.6 \times 10^{-3}$ to $1.4 \times 10^{-3} \mathrm{~mol} \mathrm{dm}^{-3}$ at constant [HA], $\left[\mathrm{H}^{+}\right]$at $303 \mathrm{~K}$ and the rates were measured (Table-1, Fig. 1). The near constancy in the value of $k_{o b s}$ irrespective of the concentration confirms the first order dependence on pyridinium fluorochromate.

Effect of varying $\boldsymbol{\alpha}$-hydroxy acid concentration: The concentration of the substrates glycolic acid, lactic acid, mandelic acid were varied in the range of $1.0 \times 10^{-2}$ to $3.0 \times$ $10^{-2} \mathrm{~mol} \mathrm{dm}^{-3}$ at $303 \mathrm{~K}$ and keeping all other reactant concentrations as constant and the rates were measured (Table-1). The rate of oxidation increased progressively on increasing the concentration of hydroxy acids. The plot of $\log \mathrm{k}_{1}$ versus $\log$ [HA] gave the slope of $1.05(\mathrm{r}=0.997), 1.02(\mathrm{r}=0.998)$ and $0.994(\mathrm{r}=0.996)$ respectively for glycolic acid, lactic acid and mandelic acid respectively (Fig. 1). Under pseudo-firstorder conditions, the plot of $1 / \mathrm{k}_{1}$ versus $1 /[\mathrm{HA}]$ were linear with a negligible intercept indicating that the intermediate formed in a slow step got consumed in a subsequent fast step.

Effect of varying perchloric acid concentration: Perchloric acid has been used as a source of $\mathrm{H}^{+}$in reaction

\begin{tabular}{|c|c|c|c|c|c|}
\hline \multicolumn{6}{|c|}{$\begin{array}{c}\text { TABLE-1 } \\
\text { EFFECT OF VARIATION OF [HA], [PFC] AND }\left[\mathrm{H}^{+}\right] \\
\text {ON THE RATE OF THE REACTION AT } 303 \mathrm{~K}\end{array}$} \\
\hline \multirow{2}{*}{$\begin{array}{c}10^{3}[\mathrm{PFC}] \\
\left(\mathrm{mol} \mathrm{dm}^{-3}\right)\end{array}$} & \multirow{2}{*}{$\begin{array}{l}10^{2}[\mathrm{HA}] \\
\left(\mathrm{mol} \mathrm{dm}^{-3}\right)\end{array}$} & \multirow{2}{*}{$\begin{array}{c}{\left[\mathrm{H}^{+}\right]} \\
\left(\mathrm{mol} \mathrm{dm}^{-3}\right)\end{array}$} & \multicolumn{3}{|c|}{$10^{5} \mathrm{k}_{1}\left(\mathrm{~s}^{-1}\right)$} \\
\hline & & & GA & LA & MA \\
\hline 0.6 & 2.0 & 0.1 & 9.12 & 13.00 & 22.56 \\
\hline 0.8 & 2.0 & 0.1 & 9.04 & 13.30 & 22.72 \\
\hline 1.0 & 2.0 & 0.1 & 9.00 & 13.50 & 22.90 \\
\hline 1.2 & 2.0 & 0.1 & 9.08 & 13.60 & 22.96 \\
\hline 1.4 & 2.0 & 0.1 & 9.10 & 13.50 & 22.62 \\
\hline 1.0 & 1.0 & 0.1 & 4.38 & 6.80 & 11.08 \\
\hline 1.0 & 1.5 & 0.1 & 6.62 & 10.29 & 16.70 \\
\hline 1.0 & 2.5 & 0.1 & 11.12 & 17.35 & 28.00 \\
\hline 1.0 & 3.0 & 0.1 & 13.42 & 20.90 & 33.40 \\
\hline 1.0 & 2.0 & 0.06 & 5.28 & 7.92 & 13.40 \\
\hline 1.0 & 2.0 & 0.08 & 7.08 & 10.40 & 18.40 \\
\hline 1.0 & 2.0 & 0.12 & 10.64 & 15.96 & 27.18 \\
\hline 1.0 & 2.0 & 0.14 & 12.48 & 18.90 & 31.60 \\
\hline
\end{tabular}
medium. The concentration of $\mathrm{H}^{+}$was varied in the range 0.06

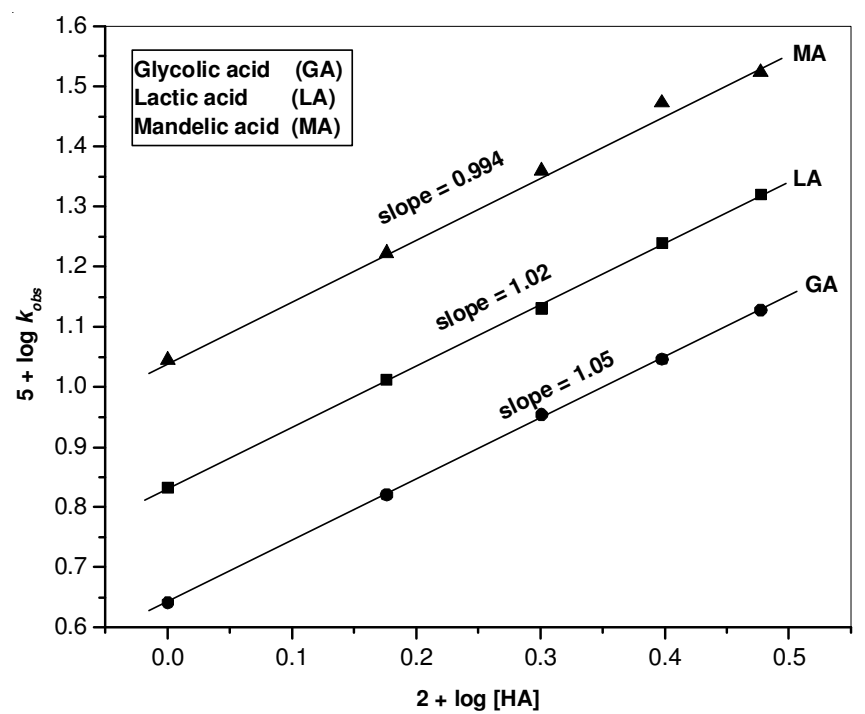

Fig. 1. Showing order plot of $\alpha$-hydroxy acids for the oxidation of hydroxy acids by PFC

to $0.14 \mathrm{~mol} \mathrm{dm}^{-3}$ keeping all other reactant concentration as constant at $303 \mathrm{~K}$ and the rates were measured (Table-1). The acid catalyzed nature of this oxidation is confirmed by an increase in the rate on the addition of $\mathrm{H}^{+}$. The plot of $\log \mathrm{k}_{1}$ versus $\log \left[\mathrm{H}^{+}\right]$is a straight line with the slope of $1.0(\mathrm{r}=$ $0.999), 0.998(\mathrm{r}=0.996)$ and $1.0(\mathrm{r}=0.996)$ respectively for glycolic acid, lactic acid and mandelic acid respectively. Therefore, order with respect to $\mathrm{H}^{+}$is one for glycolic acid, lactic acid and mandelic acid respectively. Pyridinium fluorochromate may become protonated in the presence of acid. The protonated pyridinium fluorochromate may function as an effective oxidant.

Induced polymerization of acrylonitrile: Vinyl monomers like acrylonitrile are added to the reaction mixture under nitrogen atmosphere to find out whether the reaction under investigation involves the formation of free radicals as the reaction intermediates. In the present study, freshly distilled acrylonitrile free from inhibitor is added to the reaction mixture containing $0.1 \mathrm{M}$ perchloric acid. After the completion of the reaction, the reaction mixture is diluted with methanol to 
observe the formation of polymer. It is observed that the oxidation reaction does not induce the polymerization (Table2). Thus, a one-electron oxidation giving rise to free radicals is unlikely.

Effect of varying ionic strength on reaction rate: The ionic strength of the reaction medium is changed by the addition of anhydrous sodium perchlorate and the influence of ionic strength on the reaction rate has been studied. The values of the rate constants at different ionic strength of the reaction medium has no significant effect on the reaction rate (Table -3).

TABLE-2

EFFECT OF ACRYLONITRILE (AN) ON THE OXIDATION OF HYDROXY ACIDS BY PYRIDINIUM FLUOROCHROMATE AT $303 \mathrm{~K}$

\begin{tabular}{cccc}
\hline $\begin{array}{c}10^{3}[\mathrm{AN}] \\
\left(\mathrm{mol} \mathrm{dm}^{-3}\right)\end{array}$ & GA & LA & MA \\
\cline { 2 - 4 } & 9.00 & 13.50 & 22.90 \\
\hline 0.0 & 9.10 & 13.48 & 22.96 \\
1.0 & 8.90 & 13.44 & 22.94 \\
2.0 & 9.12 & 13.36 & 22.88 \\
3.0 & 9.08 & 13.40 & 22.80 \\
4.0 & 9.16 & 13.52 & 22.86 \\
5.0 & \multicolumn{3}{c}{$\left.\mathrm{s}^{-1}\right)$} \\
\hline $10^{2}[\mathrm{HA}]=2.0$ mol dm$^{-3} ; 10^{3}[\mathrm{PFC}]=1.0 \mathrm{~mol} \mathrm{dm}^{-3} ; 10\left[\mathrm{H}^{+}\right]=1.0 \mathrm{~mol}$ \\
$\mathrm{dm}^{-3} ;$ Solvent composition $=50 \% \mathrm{AcOH}-50 \% \mathrm{H}_{2} \mathrm{O}(\mathrm{v} / \mathrm{v})$
\end{tabular}

TABLE-3

EFFECT OF IONIC STRENGTH ON THE OXIDATION OF HYDROXY ACIDS BY PFC AT $303 \mathrm{~K}$

\begin{tabular}{cccc}
\hline \multirow{2}{*}{$10^{2}\left[\mathrm{NaClO}_{4}\right]$} & \multicolumn{3}{c}{$10^{5} \mathrm{k}_{1}\left(\mathrm{~s}^{-1}\right)$} \\
\cline { 2 - 4 } & $\mathrm{GA}$ & $\mathrm{LA}$ & MA \\
\hline 0.0 & 9.00 & 13.50 & 22.90 \\
1.0 & 9.00 & 13.36 & 22.88 \\
2.0 & 8.90 & 13.38 & 22.82 \\
3.0 & 9.12 & 13.44 & 22.96 \\
4.0 & 9.08 & 13.56 & 22.92 \\
5.0 & 9.16 & 13.32 & 22.94 \\
\hline
\end{tabular}

$10^{2}[\mathrm{HA}]=2.0 \mathrm{~mol} \mathrm{dm}^{-3} ; 10^{3}[\mathrm{PFC}]=1.0 \mathrm{~mol} \mathrm{dm}^{-3} ; 10\left[\mathrm{H}^{+}\right]=1.0 \mathrm{~mol}$ $\mathrm{dm}^{-3} ;$ Solvent composition $=50 \% \mathrm{AcOH}-50 \% \mathrm{H}_{2} \mathrm{O}(\mathrm{v} / \mathrm{v})$

Effect of acidity: The reaction is catalyzed by hydrogen ions (Table-1). The acid-catalysis may well be attributed to a protonation of pyridinium fluorochromate to give a stronger oxidant and electrophile.

$$
\mathrm{O}_{2} \mathrm{CrFO}-\mathrm{PyH}^{+}+\mathrm{H}^{+} \rightleftharpoons(\mathrm{OH}) \mathrm{OCrFO}-\mathrm{PyH}^{+}
$$

The formation of a protonated $\mathrm{Cr}(\mathrm{VI})$ species has earlier been postulated in the reactions of structurally similar pyridinium chlorochromate ${ }^{20}$ and pyridinium fluorochromate ${ }^{21}$.

Kinetic isotope effect: To ascertain the importance of the cleavage of the $\alpha-\mathrm{C}-\mathrm{H}$ bond in the rate-determining step, oxidation of $\alpha$-deuterio mandelic acid (DMA) was studied. Results showed the presence of a substantial primary kinetic isotope effect (Table-4).

Effect of solvent polarity on reaction rate: The oxidation of $\alpha$-hydroxy acid has been studied in the binary mixture of acetic acid and water as the solvent medium. For the oxidation of all hydroxy acids, the reaction rate increased remarkably with the increase in the proportion of acetic acid in the solvent medium. These results are presented in Table-5.
TABLE-4

KINETIC ISOTOPE EFFECT ON THE OXIDATION OF MANDELIC ACID BY PYRIDINIUM FLUOROCHROMATE

\begin{tabular}{lcccc}
\hline \multirow{2}{*}{ Substrate } & \multicolumn{4}{c}{$10^{5} \times \mathrm{k}_{1}\left(\mathrm{~s}^{-1}\right)$} \\
\cline { 2 - 5 } & $298 \mathrm{~K}$ & $303 \mathrm{~K}$ & $308 \mathrm{~K}$ & $313 \mathrm{~K}$ \\
\hline MA & 17.20 & 22.90 & 30.46 & 38.46 \\
DMA & 3.22 & 4.10 & 5.26 & 6.45 \\
$\mathrm{k}_{\mathrm{H}} / \mathrm{k}_{\mathrm{D}}$ & 5.34 & 5.58 & 5.79 & 5.96 \\
\hline $10^{2}[\mathrm{MA}]=2.0 \mathrm{~mol} \mathrm{dm}^{-3} ; 10^{3}[\mathrm{PFC}]=1.0 \mathrm{~mol} \mathrm{dm} \mathrm{dm}^{-3} ; 10\left[\mathrm{H}^{+}\right]=1.0 \mathrm{~mol}$ \\
$\mathrm{dm}^{-3} ;$ Solvent composition $=50 \% \mathrm{AcOH}-50 \% \mathrm{H}_{2} \mathrm{O}(\mathrm{v} / \mathrm{v})$
\end{tabular}

TABLE-5

EFFECT OF VARYING SOLVENT POLARITY ON THE RATE OF REACTION AT $303 \mathrm{~K}$

\begin{tabular}{cccccc}
\hline \multirow{2}{*}{$\begin{array}{c}\text { \% Acetic acid- } \\
\text { Water }(\mathrm{v} / \mathrm{v})\end{array}$} & $\begin{array}{c}\text { Dielectric } \\
\text { constant }\end{array}$ & 1/D & \multicolumn{3}{c}{$10^{5} \times \mathrm{k}_{1}\left(\mathrm{~s}^{-1}\right)$} \\
\cline { 4 - 6 } & 72.0 & 0.0138 & $\mathrm{GA}$ & $\mathrm{LA}$ & $\mathrm{MA}$ \\
\hline $30-70$ & 63.3 & 0.0158 & 8.10 & 12.20 & 20.68 \\
$40-60$ & 56.0 & 0.0178 & 9.00 & 13.50 & 22.90 \\
$50-50$ & 45.5 & 0.0219 & 11.44 & 16.40 & 27.96 \\
$60-40$ & 38.5 & 0.0259 & 13.80 & 19.52 & 34.78 \\
$70-30$ & &
\end{tabular}

$10^{2}[\mathrm{HA}]=2 \mathrm{~mol} \mathrm{dm}^{-3} ; 10^{3}[\mathrm{PFC}]=1 \mathrm{~mol} \mathrm{dm}^{-3} ; 10\left[\mathrm{H}^{+}\right]=1 \mathrm{~mol} \mathrm{dm}^{-3}$

The dielectric constant or permittivity $(\varepsilon)$ is a dimensionless constant that indicates how easy a material can be polarized by imposition of an electric field on an insulating material. The constant is the ratio between the actual material ability to carry an alternating current to the ability of vacuum to carry the current. The dielectric constant can be expressed as:

$$
\varepsilon=\varepsilon_{\mathrm{s}} / \varepsilon_{0}
$$

where; $\varepsilon=$ the dielectric constant; $\varepsilon_{\mathrm{s}}=$ the static permittivity of the material; $\varepsilon_{0}=$ vacuum permittivity.

The effect from solvent composition on the reaction rate was studied by varying the concentration of acetic acid from 30 to $70 \%$. The pseudo-first-order rate constants were estimated for the oxidation of hydroxyl acids, with pyridinium fluorochromate in the presence of perchloric acid at a constant ionic strength. The reaction rate is increases markedly with the increase in the proportion of acetic acid in the medium (Table-5). When the acid content increases in the medium, the acidity of the medium is increased whereas the dielectric constant of the medium is decreased. These two effects cause the rate of the oxidation to increase markedly. The enhancement of the reaction rate with an increase in the amount of acetic acid generally may be attributed to two factors, viz., (i) the increase in acidity occurring at constant $\left[\mathrm{H}^{+}\right]$and (ii) the decrease in the dielectric constant with an increase in the acetic acid content.

The plot of $\log \mathrm{k}_{1}$ versus 1/D (dielectric constant) is linear with positive slope suggesting the presence of either dipoledipole or ion-dipole type of interaction between the oxidant and the substrate ${ }^{22,23}$ (Fig. 2). Plot of $\log \mathrm{k}_{1}$ versus (D-1)/(2D+1) is a curvature indicating the absence of dipole-dipole interaction in the rate determining step. Positive slope of $\log \mathrm{k}_{1}$ versus $1 / \mathrm{D}$ plot indicates that the reaction involves a cation-dipole type of interaction in the rate determining step.

Amis $^{24}$ holds the view that in an ion-dipole reaction involving a positive ionic reactant, the rate would decrease with increasing dielectric constant of the medium and if the reactant were to be a negatively charged ion, the rate would 
TABLE-6

ACTIVATION PARAMETERS AND SECOND ORDER RATE CONSTANTS FOR THE

OXIDATION OF HYDROXY ACIDS BY PFC IN AQUEOUS ACETIC ACID MEDIUM

\begin{tabular}{|c|c|c|c|c|c|c|c|c|}
\hline \multirow{2}{*}{ Substrate } & \multicolumn{4}{|c|}{$10^{3} \mathrm{k}_{2}\left(\mathrm{dm}^{3} \mathrm{~mol}^{-1} \mathrm{~s}^{-1}\right)$} & \multirow{2}{*}{$\begin{array}{c}\mathrm{E}_{\mathrm{a}} \\
\left(\mathrm{kJ} \mathrm{mol}^{-1}\right)\end{array}$} & \multirow{2}{*}{$\begin{array}{c}\Delta \mathrm{H}^{\#} \\
\left(\mathrm{~kJ} \mathrm{~mol}^{-1}\right) \\
\end{array}$} & \multirow{2}{*}{$\begin{array}{c}-\Delta \mathrm{S}^{\#} \\
\left(\mathrm{JK}^{-1} \mathrm{~mol}\right)\end{array}$} & \multirow{2}{*}{$\begin{array}{c}\Delta \mathrm{G}^{\#}\left(\mathrm{~kJ} \mathrm{~mol}^{-1}\right) \\
\quad(\text { at } 303 \mathrm{~K})\end{array}$} \\
\hline & $298 \mathrm{~K}$ & $303 \mathrm{~K}$ & $308 \mathrm{~K}$ & $313 \mathrm{~K}$ & & & & \\
\hline GA & 3.40 & 4.50 & 6.00 & 8.40 & 46.52 & 43.84 & 144.92 & 87.87 \\
\hline LA & 5.40 & 6.75 & 8.72 & 11.60 & 38.30 & 36.95 & 164.46 & 86.78 \\
\hline MA & 8.60 & 11.45 & 15.23 & 19.23 & 41.93 & 39.44 & 151.72 & 85.41 \\
\hline
\end{tabular}

$10^{2}[\mathrm{HA}]=2.0 \mathrm{~mol} \mathrm{dm}{ }^{-3} ; 10^{3}[\mathrm{PFC}]=1.0 \mathrm{~mol} \mathrm{dm}^{-3} ; 10\left[\mathrm{H}^{+}\right]=1.0 \mathrm{~mol} \mathrm{dm}{ }^{-3} ;$ Solvent composition $=50 \% \mathrm{AcOH}-50 \% \mathrm{H}_{2} \mathrm{O}(\mathrm{v} / \mathrm{v})$

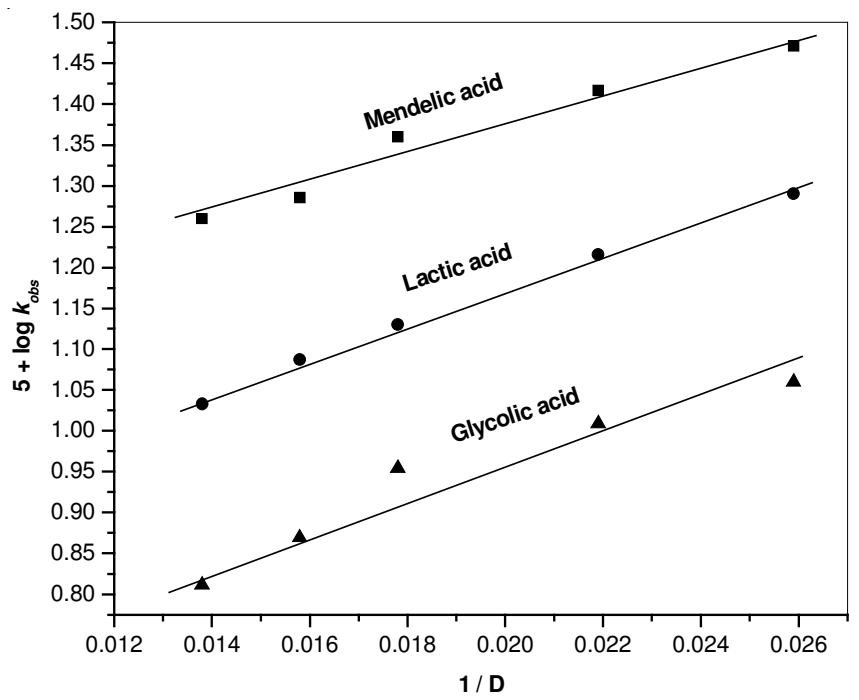

Fig. 2. Plot of $1 / \mathrm{D}$ against $\log \mathrm{k}_{\mathrm{obs}}$ showing effect of solvent polarity

increase with the increasing dielectric constant. In this case, there is a possibility of a positive ionic reactant, as the rate decreases with the increasing dielectric constant of the medium $^{24}$. Due to the polar nature of the solvent, transition state is stabilized, i.e., the polar solvent molecules surround the transition state and result in less disproportion.

Thermodynamic parameters: The kinetics of oxidation of hydroxy acids was studied at four different temperatures viz., 298, 303, 308 and $313 \mathrm{~K}$. The second order rate constants were calculated (Table-6). The Arrhenius plot of $\log \mathrm{k}_{2}$ versus $1 / \mathrm{T}$ is found to be linear. The enthalpy of activation, entropy of activation and free energy of activation were calculated from $\mathrm{k}_{2}$ at 298, 303, 308 and $313 \mathrm{~K}$ using the Eyring relationship by the method of least square and presented in Table- 6 . The entropy of activation is negative for hydroxyl acids. The negative entropy of activation in conjunction with other experimental data supports the mechanism outlined in Scheme-I.

Isokinetic relationship: The reaction is neither isoenthalpic nor isoentropic but complies with the compensation law also known as the isokinetic relationship.

$$
\Delta \mathrm{H}^{\#}=\Delta \mathrm{H}^{\mathrm{o}}+\beta \Delta \mathrm{S}^{\#}
$$

The isokinetic temperature $\beta$ is the temperature at which all the compounds of the series react equally fast. Also, at the isokinetic temperature, the variation of substituent has no influence on the free energy of activation. Exner ${ }^{25}$ suggested a method of testing the validity of isokinetic relationship. The isokinetic relationship is tested by plotting the logarithms of rate constants at two different temperatures $\left(T_{2}>T_{1}\right)$ against each other according to eqn. 4.<smiles>O=[Cr](=O)(F)O[PH3+]</smiles><smiles>[R]C(O)C(=O)O</smiles>

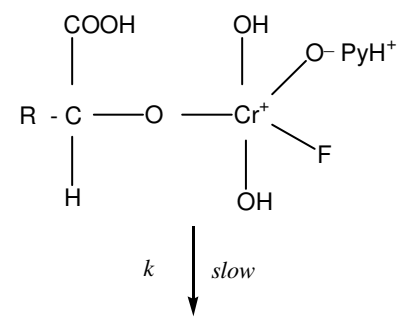<smiles></smiles>

Scheme-I: Mechanism of oxidation of hydroxy acids by pyridinium fluorochromate

$$
\log \mathrm{k}\left(\text { at } \mathrm{T}_{2}\right)=\mathrm{a}+\mathrm{b} \log \mathrm{k}\left(\text { at } \mathrm{T}_{1}\right)
$$

The linear relationship in Exner plots ${ }^{26,27}$ at $4+\log \mathrm{k}_{2}$ $(303 \mathrm{~K})$ and $4+\log \mathrm{k}_{2}(308 \mathrm{~K})$ observed in the present study imply the validity of the isokinetic relationship. Isokinetic temperature obtained is $418 \pm 12 \mathrm{~K}$. The linear isokinetic correlation implies that glycolic acid, lactic acid and mandelic acid are oxidized by the same mechanism and the changes in the rate are governed by the changes in both the enthalpy and entropy of activation ${ }^{28}$.

Mechanism of oxidation: From the product analysis, 2,4dinitro phenyl hydrazone was confirmed. Hence, it shows that under the experimental conditions employed in the present study, $\alpha$-hydroxyl acids were oxidized to the corresponding oxo acids. Based on the above kinetic observations the following mechanism is proposed for the reaction. Absence of any effect of added acrylonitrile on the reaction discounts the possibility of a one-electron oxidation, leading to the formation of free radicals. The presence of a substantial kinetic isotope effect in the oxidation of DMA confirms the cleavage of the $\alpha-\mathrm{C}-\mathrm{H}$ bond in the rate-determining step. Therefore, a hydride-ion transfer in the rate determining step is suggested (Scheme-I).

\section{Conclusion}

The kinetics of oxidation of $\alpha$-hydroxy acids has been investigated in aqueous acetic acid medium in the presence of 
pyridinium fluorochromate by spectrophotometrically at 303 $\mathrm{K}$. The oxidation of $\alpha$-hydroxy acids by pyridinium fluorochromate is first order each with respect to the hydroxy acids, pyridinium fluorochromate and hydrogen ion. The oxidation is catalyzed by mineral acid. The lowering of dielectric constant of reaction medium increases the reaction rate significantly. The ionic strength of the reaction medium does not affect the rate of the oxidation. The reaction does not shows the polymerization, which indicates the absence of free radical intermediate in the oxidation. The order of reactivity is glycolic acid $<$ lactic acid $<$ mandelic acid. The reaction rate is higher in lactic acid than in glycolic acid due to the inductive effect. Enhanced reactivity in mandelic acid may be due to the stabilization of the intermediate formed through resonance.

\section{REFERENCES}

1. K.B. Wiberg, Oxidations in Organic Chemistry, Academic Press, New York (1965)

2. E.J. Corey and D.L. Boger, Tetrahedron Lett., 28, 2461 (1978).

3. N. Narayanan and T.R. Balasubramanium, J. Chem. Res (S), 336 (1991).

4. G. Fathimajeyanthi, G. Vijayakumar and K.P. Elango, J. Serb. Chem. Soc., 67, 803 (2002).

5. S.S. Mansoor, Asian J. Chem., 22, 7591 (2010).

6. V. Dhariwal, D. Yajurvedi and P.K. Sharma, Indian J. Chem., 45A, 1158 (2006).

7. A. Pandurangan, V. Murugesan and M. Palanisamy, J. Indian Chem. Soc., 72, 479 (1995).
8. M.N. Bhattacharjee, M.K.Chaudhuri, H.S. Dasgupta, N. Roy and D.K. Khathing, Synthesis, 588 (1982).

9. S.S. Mansoor and S.S. Shafi, Reac. Kinet. Mech. Cat., 100, 21 (2010).

10. S.S. Mansoor and S.S. Shafi, J. Mol. Liq., 155, 85 (2010).

11. S.S. Mansoor and S.S. Shafi, Int. J. Chem. Tech. Rech., 1, 1207 (2009).

12. S.S. Mansoor and S.S. Shafi, E-J. Chem., 6, S522 (2009).

13. V. Kumbhat, P.K. Sharma and K.K. Banerji, Int. J. Chem. Kinet., 34, 248 (2000)

14. K.K. Sen Gupta, Int. J. Chem. Kinet., 31, 873 (1999).

15. A. Goyal and S. Kothari, Bull. Chem. Soc. (Japan), 76, 2335 (2003).

16. N. Nalwaya, A. Jain and B.L. Hiran, Oxid. Commun., 26, 561 (2003).

17. S. Meenashisundaram and V. Sathiyendiran, Oxid. Commun., 21, 71 (1998).

18. D. Garg and S. Kothari, J. Chem. Sci., 26, 333 (2004).

19. N. Malani, M. Baghmar, P. Swami and P.K. Sharma, Prog. React. Kinet. Mechan., 33, 392 (2008).

20. V. Sharma, P.K. Sharma and K.K. Banerji, J. Indian Chem. Soc., 74, 607 (1997).

21. V. Sharma, P.K. Sharma and K.K. Banerji, J. Chem. Res. (S), 290 (1996).

22. G. Scatchard, Chem. Rev., 10, 229 (1932).

23. G. Scatchard, J. Chem. Phys., 7, 657 (1939).

24. E.S. Amis, Solvent Effects on Reaction Rates and Mechanisms, Academic Press, New York, p. 42 (1967).

25. D.S. Bhuvaseshwari and K.P. Elango, Int. J. Chem. Kinet., 39, 657 (2007).

26. O. Exner, Nature, 201, 488 (1964).

27 O. Exner, J.R. Streitwiser and R.W. Talt, 41 Progress in Physical Organic Chemistry, John Wiley, New York (1973).

28. J.F. Leffler and E. Grunwald, Rates and Equilibrium of Organic Reactions, Wiley, New York (1963). 